\title{
The Marriage Between Advertising Text and Literature
}

\author{
Yu Zhao ${ }^{1, a}$, Rui Jie Duan ${ }^{2, b^{*}}$ \\ ${ }^{I}$ School of Chinese Language and Literature, Nanjing Xiaozhuang University, Jiangning, Nanjing, Jiangsu, China \\ ${ }^{2}$ Liuzhou Emergency Management Bureau, Chengzhong, Liuzhou, Guangxi, China \\ a2671491398@qq.com \\ b*649410338@qq.com
}

\begin{abstract}
With the progress and development of the times, advertising communication has gradually become an increasingly important means of communication. Advertising copy-writing is an important part of advertising, and its popularity has become the standard for the success of advertising. This dissertation mainly uses the era of the whole media as the research background, discusses the literariness of advertising copy in the era of full media, explores the relationship between advertising copy and literature, and seeks the epoch-rich reason for advertising copy. It reveals the benefits of the fusion of advertising utilitarianism and literary non-utilitarian purposes. Therefore, the author hopes to start with the relationship between advertising copy and literature, and explore the reasons and significance of the marriage between the two.
\end{abstract}

Keywords: Advertising text, Literature, Marriage

\section{INTRODUCTION}

Modern media is quietly changing the world. As the most eye-catching form of communication in the media era, advertising and mass media depend on and promote each other, and penetrate into every corner of mass daily life. Advertising is also divided into commercial advertising and public service advertising.

The main function of commercial advertising is to transmit commodity information and accurately locate commodities to the target audience. Advertising can't do much without the mass media. Similarly, advertisers also rely on the expansion of the living space of mass media, so the two complement each other. With the development of modern high technology, the development of modern advertising industry is becoming more and more rapid. As the main part of today's advertising, commercial advertising copy will also be an important means to effectively spread the communication information to the audience. Nowadays, fast food culture in the mass media is full of it. In order to highlight commodities and deepen the publicity effect, we must use the artistic means of literature to carry the information conveyed by advertising in a variety of ways. It is also the literary language that makes the advertising copy creative and charming, which effectively strengthens the influence of advertising. People also reflect their support for the literary creative advertising copy. Therefore, the literariness of advertising copy began to be concerned.

The commodities displayed in commercial advertisements can not only achieve the satisfaction of material possession, but also enjoy the illusory satisfaction of desire, which is very similar to the spiritual longing of literature and art. A full understanding of modern commercial advertising can understand the lifestyle and consumption concept of this society. Compared with commercial advertising, public service advertising is less utilitarian, more artistic, and more conveys the correct social moral ideas. However, both commercial advertisements and public service advertisements contain rich values, which will directly or indirectly affect the audience's behavior and value orientation. As the most critical part of advertising, the blurring of the edge between advertising and literature has produced a new literary type - advertising literature. In the current all media era, traditional literature is facing the impact of the emerging communication mode with the network as the main media, and the boundary between elegant art and popular art is not invariable, It will constantly blur the boundaries according to social changes and cultural development, and the literary and artistic nature of advertising copy will inevitably be paid attention to. 
With the progress and development of the times, advertising communication has gradually become an increasingly important way of communication. As an important part of advertising, the public acceptance of advertising copy has become the standard of whether advertising is successful or not. After simple and repeated text development, advertising copy has gradually evolved to today's literary text, which has metaphorically transformed the goods, and a series of literary and artistic skills are applied to the goods to make the goods consistent with the public's mentality and interests, which realizes the marriage between advertising copy and literature. Taking the all media era as the research background, this paper deeply discusses the literariness of advertising copy in the all media era, reveals the relationship between advertising copy and literature, and seeks the era reasons rich in literariness in advertising copy, so as to reveal the benefits of the integration of advertising utilitarian and literary non utilitarian purposes. Therefore, the author hopes to explore the reason and significance of their marriage from the relationship between advertising copy-writing and literature.

\section{THE MARRIAGE BETWEEN ADVERTISING COPY-WRITING AND LITERATURE}

Advertising is an important carrier for the construction of commodity image. The construction of advertising commodity image exists in creative advertising copy, which is often expressed through the combination of sound, picture, text and so on. Advertising Copy-writing often relies on the expression of literature and art to achieve its desired communication effect. The copy-writing that can shock the hearts of the audience is the meaningful copy-writing, and the copywriting that can stimulate the purpose of product sales is the copy-writing that can achieve its communication effect. If the advertising copy wants to produce meaning accurately, it must consider the specific social and cultural background, let the audience constantly read, watch and finally accept the advertising copy in the general environment, and understand the connotation it wants to express.

The traditional way of literary reception needs to concentrate and calm down to read and think, while the way of advertising reception is very different. Reading and watching advertising do not need to concentrate, and advertising just grabs the audience to deepen their impression through quick reading and frequent jumping. In the media age when fast food culture is popular, a large number of communication information is filled with the public's eyes and ears, so that the public will not have much interest in reading elegant literary works. However, advertisements appear in the form of "leftover materials" and are read by people in daily life such as TV dramas and films, This form provides another possibility for reading literary works.

\subsection{Literariness of Advertising Copy}

To achieve the literary aesthetic pursuit of advertising copy, the first thing to bear the brunt is the literariness of advertising copy. Although today's advertising pays more and more attention to the impact of sound, picture hearing and visual effect on the audience, advertising language rich in literary meaning is always essential in advertising. From beginning to end, the purpose of advertising communication runs through it. At the beginning, the shouting oral promotion was simple and repeated. Basically, there was no creativity, but simply selling goods. Later, advertising gradually developed into a mode of dialogue with consumers to achieve the purpose of product promotion through the poetic description of products or services. Along the way, its aesthetic significance has gradually become clear, indicating that advertising copy is developing in the direction of literariness, and the actual communication effect of advertising is more reflected in the pursuit of literary aesthetics. The literariness of advertising copy refers to the effect of "Defamiliarization" felt by the audience through the extensive use of rhetoric, metrical rules, extraordinary combination of words and other methods, or creating attractive images to bring beautiful enjoyment and spiritual pleasure to the audience.

At the same time, there are great differences between advertising copy-writing language and literary language. The first is its different functions and purposes. As the carrier of literary works, literary language is generally the expression or catharsis of personal emotion and experience. The function of literary language is to let the audience infect their emotions, resonate with the works, and play a role of aesthetic sharing or warning education. Most of them have no practical value and utilitarian. However, the purpose of advertising copy language is to publicize products and the company's image. Advertising copy makes the audience produce an illusory and beautiful experience through the expression of language and the structure of plot, entices the audience to pay attention to the works, and finally buy products. It is relatively utilitarian and will have higher practical value. The second is the different ways of creation. Literary language itself can freely form a real or non real world. In literary works, writers can imagine freely and freely. The language of advertising copy is subject to the products it promotes. The copy can only be created by extracting its uniqueness around the characteristics and services of the product. The advertising copy itself is a "dance in shackles". Finally, the language meaning of literary works is different. The language of literary works often has multiple meanings, and there may be a variety of different interpretation methods in the process of text interpretation. In order to quickly achieve its publicity 
goal, advertising copy-writing language can only choose simple and understandable language expression, so that the audience can understand the meaning of advertising without effort.

Being able to express the surface meaning clearly and accurately is the basic requirement of people in the process of using language for communication. On top of this requirement, we should also strive to express the vivid image. What can leave a deep impression is the sentences that can make people feel the charm and beauty conveyed by the language. The flexible rhetoric in advertising language makes full use of the broad and profound rhetoric skills of Chinese language, which can fully improve the aesthetics of advertising language and achieve twice the result with half the effort. For example, the famous advertising slogan of Dove chocolate: "milk is fragrant, silky feeling". When you taste Dove chocolate, the fragrant milk flavor contained in chocolate is like silk dancing around you. Using the feeling of silky smoothness and softness to describe the silky and fragrant delicate taste of Dove chocolate after it is imported can be described as the acme of rhetoric in the advertising slogan, Not stick to one style, high artistic conception. With such wonderful advertising language that can give people a unique feeling, more and more people all over the world can convey their silk like love through Dove chocolate. The use of beautiful rhymes in advertising language can enhance the musical beauty of advertising language and highlight the product image. For example, the advertising language of Tuopai Liquor: "long years of wine, Didi Tuopai music", in which the two overlapping words "youyou" and "didi" are used to make the audience have a tortuous sense of music when reading the advertising language, and give people a sense of historical massiness, not only the aroma of Tuopai Liquor, It can also make people feel an unspeakable cultural aroma. The audience can also be impressed by more poetic expression in the advertising copy. For example, the advertising language of Shanxi Xinghua village wine: "ask where the restaurant is, and the shepherd boy points to Xinghua village from afar". This advertising copy is quoted from Du Mu's poem Qingming, which makes full use of the music of literary language and makes people catchy, The Xinghua village in the advertising copy no longer points to a village, but points out the product brand, so that the audience can unconsciously associate the brand of Xinghua village wine when mentioning poetry. In terms of the extraordinary combination of words, advertising language breaks through the conventional usage, deconstructs and even subverts the grammar, so as to emphasize the novelty of advertising language and highlight the flexibility and liveliness of product image. Often this kind of language can maximize the "strangeness" effect of the audience. For example, the Chinese version of Adidas, a famous sports brand, says: "no basketball, no brother". This sentence explains the team spirit contained in basketball, but "no" in "no brother" is an adverb, while "brother" is a noun. According to Chinese grammar rules, adverbs cannot directly modify nouns. This is the subversion of grammar, that is to say, "no brother" uses a wrong grammar. However, different from literary language, advertising language is not limited by these customary grammatical rules. It can attract the attention of the audience by shocking the common customs. This advertising language is also loved and supported by the majority of basketball lovers and even other sports lovers because it accurately interprets the essence of sports.

The classic advertising language we see that can spread for a long time is because of the charm of language, which makes them catchy and memorable and become a model of advertising language. These advertising copywriting can very clearly express the charm and characteristics of commodities, and carry out certain aesthetic packaging for products. These languages directly make the audience's mind and the charm expressed by commodities have aesthetic resonance, so as to identify and purchase the commodities advertised. It is not difficult to see that the task of many commercial advertisements today is no longer just to sell goods directly and simply, but to create them through nonstandard models, and use the poetic presentation of expression to move the hearts of the audience and make the audience resonate and desire.

\subsection{Image of Advertising Copy}

In order to achieve the literary aesthetic pursuit of advertising copy, the second important thing is the image of advertising copy. The shaping of advertising image is the key to the success of advertising creation and the sale of goods. The marketing of products through image is also the strategy for advertising to locate the product to which audience group. It is precisely because the logical language is not easy to perfectly express the meaning in the heart of the advertising creator, so the advertising copywriter pays more attention to imagery. In this case, advertising can often "stand an image to convey meaning". For example, Liqun's cigarette advertisement "life is like a journey. You don't have to care about the destination. You care about the scenery along the way and the mood of watching the scenery. Let your heart travel Liqun". In the advertisement, a train drove slowly through the calm grassland outside the Great Wall in the scorching sun, with no clouds and vast smoke. At this time, a walker was on the train calmly watching the scenery passed by the train, just as the years of life remained in the scenery behind him, while the train of time was slowly leaving. This is the quiet, peaceful and long-lasting experience and feeling given to the audience by Liqun brand advertising words. Different from the straightforwardness of some advertising copy-writing, Liqun uses the unique implicit meaning of Chinese 
culture, not a word on the product, and uses prose language to slowly monologue, but it is deeply rooted in the hearts of the people. Cigarettes can not only release their pressure from the senses and body, but also release them from the spirit. This kind of advertisement that tells the voice of men is naturally more popular. In the creation of this elegant and quiet advertising image, it skillfully integrates the publicity of cigarette products and the audience's secondary exploration of corporate cultural image, and the artistic conception created by advertising is long and memorable.

Through the use of extended meaning, metaphor and other forms of language, we can also express the images that advertising wants to show. This type of advertising copy will fully rely on the cultural connotation of language and the collocation of words, so as to give advertising more connotation and leave a deeper impression on the audience. For example, the slogan of farmer's mountain spring mineral water: "think of the source when drinking water, farmer's mountain spring". Chairman Mao once said: "think of the source when drinking water, and don't forget the well digger when drinking water". Farmer's mountain spring mineral water promised to donate a penny to poor mountainous areas every time it sold a bottle of water, so it skillfully publicized the charity heart of farmer's mountain spring enterprise through the extended meaning of "think of the source when drinking water", It is hoped that this approach can exchange the recognition of more audiences and turn the audience into consumers. Metaphor is a form of expression that directly refers to the metaphor as the cost. For example, the advertising language of a diamond watch: "the messenger of time", which compares the watch to a messenger. If people want to have time, they should have a diamond watch, because the diamond watch is the messenger of time. Under the action of metaphor, the watch is the messenger or even time. Diamond watches are not reflected in advertising language from beginning to end, but metaphor makes ontology and metaphor have the same characteristics in one aspect, and connects them through ingenious overlapping. Another example is the advertisement of Longhu real estate: "Longhu Garden: going home is the beginning of vacation". This advertisement makes full use of the cultural connotation of home in traditional culture. In the eyes of Chinese people, home is not only the driving force of work and struggle, but also the harbor of soul and the place of stability for a lifetime. Longhu real estate has further sublimated the concept of home, making its image more comfortable and comfortable. Although there is no separate description of the landscape of Longhu garden, However, this advertising language describes people's ideal home more perfectly and more eagerly. In this way, the image constructed by language can successfully promote the marketing of products.

\subsection{Humanistic Pursuit of Advertising Copy}

If you want to achieve the literary aesthetic pursuit of advertising copy, you must have the humanistic pursuit of advertising copy. "Gorky, a famous Russian writer, first put forward the view that 'literature is humanism' in talking about skills in July 1931. He believes that peoplecentered social life is the reflection object of literature. The writer's unique taste of life always runs through the process of literary creation, and the writer's purpose of literary creation is always to improve and perfect people." [1] In this way, literary works are created to meet people's needs, and the objects of literary works are basically real life with human theme, which is similar to the creation of Advertising Copy-writing. The relationship between advertising communication process and people is inseparable. In order to achieve the purpose of effective advertising communication, the meaning of advertising is to attract the attention of the audience. We can see that the entry point of more and more advertisements is changed to human emotion, from "goods" to "people". The humanistic pursuit of advertising copy is becoming more and more obvious, which makes the audience deeply impressed with the goods. Finally, we try to transform the audience into consumers and promote their purchase behavior. It can be said that the commodity promotion in advertising is the most basic function, but this basic function cannot exist independently. Sometimes it just needs non economic means to give full play to its promotion function. Nowadays, many advertisements we usually see contain humanistic spirit. Next, I will analyze the humanistic pursuit of Advertising Copy-writing from two aspects: commercial advertising and public service advertising.

Public service advertisements refer to public services that do not aim at profit and service advertisements that pay attention to social interests and social public morality. The value orientation of public service advertisements is human centered. Therefore, it can be said that public service advertisements are humanistic. For example, the public service advertisement "respect, love and help the elderly series" broadcast on CCTV: "treating the elderly well is treating yourself well tomorrow". This advertisement copy deeply reflects the word "filial piety". "Filial piety" is a traditional virtue of our Chinese nation. Filial piety can be reflected in every bit of life. When we are free at home, we can wash clothes and cook for our parents and elders. If we do more, our elders can do less. People will grow old one day. Parents' filial piety to their elders is to set an example for their children. Parents are the best teachers in the formation of children's behavior and character. Their words and deeds will affect their children. Parents' filial piety to their elders will imperceptibly teach children to be filial to their elders. Therefore, the power of example is infinite. In the creation of public service advertisements, CCTV 
skillfully uses the culture of filial piety, adopts the content and methods most easily accepted by the audience, and uses euphemistic and implicit means of expression to achieve the best publicity effect, warning the Chinese people not to forget and live up to the traditional virtues of the Chinese nation, and should inherit and carry forward the fine tradition of "putting filial piety first". In addition to this public service advertisement, the public service advertisement copy is also paying more attention to social problems such as environmental protection, smoking, project hope, traffic driving and so on. The purpose of public service advertising is to promote the transmission of social positive energy, urge the public to pay attention to the existing social problems, and advocate positive social values, so as to form a healthy social fashion. In public service advertising, the pursuit of humanistic value in advertising copy can be reflected in people's care, love and respect.

Commercial advertisement is an advertisement made by businesses in order to obtain benefits. Its purpose is to promote a product or service and let the audience consume it. In commercial advertising, the performance of humanistic pursuit is complex and diverse. One is emotional care. For example, China Unicom's advertising copy "is China complex and China Unicom's universal heart." A huge red Chinese knot is the symbol of China Unicom. At the same time, the Chinese knot element is also full of affinity for Chinese people. Compared with the contribution of China Mobile and China Telecom to the development of China's communication service industry, China Unicom also provides its indelible strength. This advertising copy is rooted in the traditional culture of the Chinese nation's "unity of heaven and man". China Unicom closely connects the hearts of Chinese people all over the world. The feeling of reunion and homesickness that Chinese people yearn for are vividly expressed in just ten words. At the same time, Unicom naturally integrates the logo and name into this advertising language, achieves harmony and unity from inside to outside, reflects the enterprise's brand concept, and is easier to be recognized by the advertising audience. We can feel that Unicom's efforts are to connect more people and more Chinese feelings, so as to resonate emotionally with Unicom's ideas, which will make the audience have a sense of identity and closeness to the brand of Unicom. When choosing communication services, they will naturally choose these brands with a sense of identity and closeness that they can remember. The other is the embodiment of life values and free personality, such as MetS bonway's advertising slogan "taking an unusual road". This is a very personalized advertising language, and MetS bonway's products are mainly college students' clothes. It is a brand that wants to publicize personality, fashion and fashion, and show youth and vitality at the same time. This advertising language does not have any words to reflect the product, but the short sentence reflects the flavor of the times belonging to the young generation that is full of youth and vitality, self-confidence and personality of contemporary young people. This advertisement is a typical embodiment of the values and personality of the new generation of young people. The more the positioning of the company and brand conveyed through the advertisement fits with the recognition psychology of the audience, the more resonance can be generated between the audience and the product, which can make it easier for the audience to form the corresponding brand preference.

\section{REASONS FOR THE AARRIAGE BETWEEN ADVERTISING COPY- WRITING AND LITERATURE}

\section{1 the Era of "All Media" Promotes the Integration of Forms of Expression}

The concept of "all media" has not been put forward as a professional term in Foreign Journalism and communication circles, but in recent years, some journalism and communication scholars in China have begun to mention and study this concept. China's news communication scholars who define this are divided into two categories: the "theory of operation concept" represented by Peng LAN, Professor of the school of journalism of Renmin University of China, and the "theory of communication form" represented by Zhou Yang, Department of military news communication of Nanjing Institute of political science. With the change of the times and the breakthrough of technology, the concept of "all media" appears more and more in various industries and types of articles. Now the more recognized concepts are: "All media is a new form of communication, which means that in order to display media information in a more comprehensive and three-dimensional way, it will use text, image, sound, photoelectric and other forms of expression, and use a variety of multimedia communication means to transmit information. The transmitted information can be received through a variety of transmission terminals, and finally users can complete the reception of media information." Therefore, under the influence of the "all media" era, mobile phones and the Internet make the high-speed dissemination of online advertising possible. "Just as the Renaissance broke the formal boundary between religious art and secular art, online advertising broke the boundary between individuals and groups." [2] Paul Levinson, a foreign scholar, believes that: "In the past, the vast majority of electronic media were 'one-way' media, or sending information, producing information, or receiving and consuming information; when using these media, you can't speak or move when you move. The unlimited twoway communication ability of mobile phone makes it the most perfect, powerful and potential first media for 
information dissemination." [3] Internet advertising is highly interactive. It has begun to deeply affect people's daily life and closely connect people's daily life. At this time, the effectiveness of advertising information dissemination and the sense of social responsibility of the transmitted content have become the focus of more attention. Advertising is no longer just a science, but an art, This makes advertising need to pay attention to the humanistic pursuit and aesthetic non utilitarianism.

\subsection{Realistic Direction of Advertising Copy Image Consumption}

In the current era of material abundance and enjoyment, as long as there is demand, there will be creation. After money is satisfied, what people need is the consumption demand of "desire satisfaction", so what comes into being for such demand is the expression of desire satisfaction in advertising copy. As Jiang shuzhuo once said in a Book: "The core of advertising's deep involvement in daily life is to trigger people's various desires, guide consumer behavior and serve commercial circulation by using direct or indirect, or plain or poetic narrative methods. Although advertising is a marketing means, it must face people's desires directly like literature, art, religion, morality, philosophy and politics. People are the complex of desires. "In order to successfully arouse the desire of consumers, the advertising copy can convey the specific information that occurs at any time and in any space, and then look for the characteristics of the product, shape it into a part of the product image, and make the audience associate when watching. In addition, in order to strengthen the attraction of advertising to the audience, advertising copy-writing usually adopts literary expression methods. In order to enable the audience to enter the scene and atmosphere rendered by advertising when watching advertising, it often uses some literary skills, such as literary language and literary sentence patterns, to make the audience agree with the description of the product, so as to produce the desire to consume the product. For example, De Beers company automatically combines diamonds with happiness with the slogan "Diamonds last forever, one will last forever", so that the engagement diamond ring has become a traditional custom of expressing love and loyalty according to secular regulations. Everyone wants to be bathed in love, and everyone is eager to harvest permanent feelings. People can only fantasize about the future through the tangible reference of diamond. Diamond is the hardest of all materials on the earth. Nothing can destroy it, so it is a hard representative. Moreover, diamond will not deteriorate with the passage of time. It is also a representative of stability, which makes the characteristics of diamond fully meet the requirements of love. Diamond can fully meet the needs of love and serve as a solid and stable representative of love. Now, De Beers's classic advertising language still represents the rich meaning of diamond rings. Diamonds are not only a symbol of wealth, power and status, but also a symbol of people's cherish of love and their precious, eternal, loyal and unbreakable desire for love. Another famous brand Jinlilai's advertising slogan is "man's world!" The success of Jinlilai is not only due to a good name, but also due to its successful product positioning. The copywriter reflects the perseverance of Jinlilai brand for many years, positioning the product as a boutique in men's clothing, suitable for successful and distinguished men, and successfully reflects the high-end positioning of Jinlilai, This slogan also clearly shows the core value of the brand. Jinlilai has noble quality. When men wear Jinlilai's clothes, they will have more extraordinary temperament, link products with identity, and make men enjoy a respectful feeling.

\subsection{Pursuit of Creativity in Advertising Copy}

In the process of advertising information dissemination, the market is gradually developing in the direction of commercialization, entertainment, consumption and desire, and a good idea can often get twice the result with half the effort. The narrative person of advertising can be divided into three categories: the first person can make the audience have a strong sense of substitution and scene; The second person can give the audience a sense of equality and intimacy; The third person's sense of distance will become larger, but it can be combined with the omniscient perspective, expand the narrative space and give people association to a certain extent. In the production process of advertising copywriting creativity, the most important constituent element is selection and breakthrough. The creative process of advertising copy-writing is the process of discovering the unique characteristics hidden in commodities. In addition, whether there is a breakthrough in creativity is the most fundamental reason why advertising creativity can be novel and unique. For example, the slogan of seven up drink is "non Cola". Qixi faced an embarrassing situation when it was founded. Qixi adopted the anti logical thinking of positioning itself as a non Cola carbonated soda, hoping to break the monopoly of Coca Cola and Pepsi in the cola market. This practice successfully distinguishes Qixi from Coca Cola and Pepsi, This creative positioning makes Qixi the third largest carbonated beverage brand in the world and has a new market.

\section{PRACTICAL SIGNIFICANCE OF THE MARRIAGE BETWEEN ADVERTISING COPY-WRITING AND LITERATURE}

\section{1 the Literariness of Goods Meets People's Spiritual Needs}

When commodities meet people's basic material needs from the beginning, the function of commodities will further change to pay attention to people's spiritual 
needs. People's spiritual needs are based on material needs, and spiritual needs are higher-level needs higher than material needs. As analyzed by Maslow's classical hierarchy of needs theory, he divides human needs into five categories: physiological needs, security needs, social needs, respect needs and self realization needs. After the low-level needs are basically met, the high-level needs will replace the low-level needs and become the main factor to stimulate people's behavior. After countless proof, compared with living in a simple house, people living in a beautiful and tidy house will be more full of vitality and vitality; Compared with ordinary people, a kind, beautiful and sincere person is easier to realize the truth, goodness and beauty in the world. In short, people with good morality, words and deeds and people in a superior environment are more likely to have a "peak experience". Human desire is the cultural driving force to promote the development of advertising, and the unprecedented expansion of desire is the source and human foundation of advertising, "Desire redefines consumption in the traditional sense. It is not just the use value of goods to meet specific needs. On the contrary, through advertising, mass media and commodity exhibition skills, consumer culture shakes the original concept of the use or meaning of goods, endows it with new images and symbols, and comprehensively stimulates people's extensive feelings, associations and desires." [4] Therefore, advertising will create a romantic atmosphere derived from reality and higher than reality through literary means, so that people can get a happy, happy and fashionable spiritual experience in this real lie that caters to the popular aesthetic taste of the times. This means that consumers are not buying brands of daily necessities, but buying a certain lifestyle, style and the identity of a certain group and social class through brands. Whether it is a diamond ring or perfume, the value of the product itself will be lower than its value, because the longer it will exist will be the immaterial value.

\subsection{Advertising Literature Enriches New Literary Types}

In the "all media" era, the ways of human information dissemination are becoming more and more abundant. People's demand for information diversification makes people unconsciously connect the commerciality of advertising with the culture of literature to a great extent. The blurred boundary between advertising and literature has given birth to a new literary type - advertising literature. "Advertising absorbs the characteristics of literature and art and becomes a style of Pan literature and pan art, and creative advertising copy can be regarded as a new type of advertising literature. They contain the novelty and originality of artistic ideas, skillfully express the target demands of advertising, and are suitable for the restrictions given by the goal of commodity promotion." [5] This literary type is an important cultural carrier in the current era. The combination of advertising copy and literature is bound to be paid more and more attention. Through the form of literary works, advertising literature presents advertising copy to the audience in another way, so as to highlight the cultural nature of advertising, In this way, the audience can have a deeper understanding and understanding of the commodities and enterprises involved in the advertising copy in the process of accepting the dissemination of advertising information.

\section{3 the Involvement of Literature Weakens the Utilitarian Nature of Advertising}

The function of advertising lies in the utilitarian purpose of product publicity and promotion, which is quite different from the non utilitarian purpose of literature and art. Although people often compare Advertising copy-writing with literary works, they are completely different. When literary content is involved in advertising, the utilitarian nature of advertising seems to be weakened by literariness. Money and art are closely linked by advertising, "all kinds of uncoordinated development make worthless goods set off with clever advertising, ordinary goods have a glorious and dazzling image, vulgar business purpose and noble religious sentiment" [6]. Advertising is no longer a simple commercial marketing process, but also because the literary meaning of advertising copy makes it contain a lot of aesthetic value and cultural meaning, which makes it possible to realize the utilitarian advertising appeal through non utilitarian language. At this time, the communication effect of advertising can not be measured by practicability and utilitarianism alone. The famous ROI theory in the advertising industry divides broadcasting management creation into three principles: relevance, originality and impact. "Perhaps the oldest source of advertising inspiration is literature" [7]. The new vitality brought by literature and art to advertising is the best impact on the audience.

\section{CONCLUSION}

With the progress and development of the times, advertising information communication has gradually become an increasingly important way of communication. Advertising copy, as an important part of advertising, its public acceptance has become the standard of advertising success. Advertising, as a means of product publicity and sales, is also stepping into a standardized mode. At the same time, advertising communication, as an important way of communication, its "aesthetic non utilitarianism" has attracted more and more attention from literary academia and advertising industry. As the main part of advertising, advertising copy-writing has gradually evolved into a text rich in literature after the development of simple and repeated text. Advertising is no longer a simple and direct sales of specific goods. It makes a metaphorical transformation of goods, applies a series of literary and artistic skills to 
goods, and through the cultural packaging of specific goods, The purpose and appeal of advertising are metaphorically transmitted to the audience, so that the goods are consistent with the mentality and interests of the audience, and obtain the dual satisfaction of material and spirit when purchasing goods, which realizes the marriage between advertising copy-writing and literature. Taking the "all media" era as the research background, a new literary type advertising literature was born under the impact of the edge fuzziness of advertising and literature. This paper makes an in-depth discussion on the advertising copy-writing in this era, reveals the relationship between advertising copy-writing and literature, and seeks the era reasons rich in literature in advertising copy-writing. Thus, it reveals the benefits of the integration of the utilitarian purpose of advertising and the non utilitarian purpose of literature. However, the ways and means of human information communication are still constantly updated and improved. In the face of the aesthetic fatigue of the public in modern society due to receiving too much information communication, it is still of great practical significance to realize the "aesthetic non utilitarian" of advertising copy, and to study the marriage between advertising copy and literature.

\section{AUTHORS' CONTRIBUTIONS}

ZhaoYu(Author1): Conceptualization, Methodology, Formal Analysis, Funding Acquisition, Resources, Supervision, Writing - Review \& Editing.

Duan Rui Jie(Author 2): Data Curation, Writing Original Draft.

\section{ACKNOWLEDGMENTS}

Phased Achievements of the National Social Science Fund Project: The Research on the Literary Activities "Based on the Literary Subjects in the Field of Media" (Project Approval No.: 17BZW049)

\section{REFERENCES}

[1] Xiang Yuezhou . On the Literariness of Advertising Texts in the All Media Era [D]. Hubei University for nationalities, 2016:33

[2] Compiled by Xiaoxue.New Media Giants Predict the Future[C] China Book Business Daily, December 7, 2007.

[3] Paul Levinson.Mobile Phone: An Unstoppable Call [M].Translated by He Daokuan Renmin University of China Press, 2004 : 6

[4] [UK] Mike Featherstone: Consumer Culture and Postmodernism [M]Translated by Liu Xianming, Nanjing Yilin publishing house,2000:166 .
[5] Jiang shuzhuo and Li Fengliang.the Way of Literary Existence in the Media Age[M] .Guangxi Normal University Press. 2010 : 72.

[6] [France] Bernard gesele and rob eberg: Decoding Advertising Creativity[M] .Compiled by Shen lvbai and Huang Zhenjia ,Beijing China price publishing house. 2003: 16.

[7] [UK] Nigel Morgan and Annette Pritchard.Advertising Creativity and Design in Tourism and Leisure Industry[M].Translated by Chen Yining eta, Beijing Electronic Industry Press. $2003: 165$. 